\title{
The Abused Inhalant Toluene Increases Dopamine Release in the Nucleus Accumbens by Directly Stimulating Ventral Tegmental Area Neurons
}

\author{
Arthur C Riegel ${ }^{*, 1,2,4}$, Agustin Zapata ${ }^{3,4}$, Toni S Shippenberg ${ }^{3}$ and Edward D French' \\ 'Department of Pharmacology, College of Medicine, University of Arizona, Tucson, AZ, USA; ${ }^{2}$ Vollum Institute, Oregon Health \& Science \\ University, Portland, OR, USA; ${ }^{3}$ Intramural Research Program, Integrative Neuroscience Section, US Department of Health and Human Services, \\ National Institute on Drug Abuse, National Institutes of Health, Baltimore, MD, USA
}

\begin{abstract}
Recreational abuse of toluene-containing volatile inhalants by adolescents is a significant public health problem. The mechanisms underlying the abuse potential of such substances remain unclear, but could involve increased activity in mesoaccumbal dopamine (DA) afferents innervating the nucleus accumbens (ACB). Here, using in vitro electrophysiology, we show that application of behaviorally relevant concentrations of toluene directly stimulates DA neurons in the ventral tegmental area (VTA), but not surrounding midbrain regions. Toluene stimulation of VTA neurons persists when synaptic transmission is reduced. Moreover, unlike non-DA neurons, the magnitude of VTA DA neuron firing does not decline during longer exposures designed to emulate 'huffing'. Using dual-probe in vivo microdialysis, we show that perfusion of toluene directly into the VTA increases DA concentrations in the VTA (somatodendritic release) and its terminal projection site, the ACB. These results provide the first demonstration that even brief exposure to toluene increases action potential drive onto mesoaccumbal VTA DA neurons, thereby enhancing DA release in the ACB. The finding that toluene stimulates mesoaccumbal neurotransmission by activating VTA DA neurons directly (independently of transynaptic inputs) provide insights into the neural substrates that may contribute to the initiation and pathophysiology of toluene abuse.

Neuropsychopharmacology (2007) 32, I558-1569; doi:I0.I038/sj.npp. I30 I273; published online 10 January 2007
\end{abstract}

Keywords: inhalant abuse; ventral tegmental area (VTA); nucleus accumbens (ACB); electrophysiology; microdialysis; dopamine (DA)

\section{INTRODUCTION}

Inhalant abuse represents a major health problem because of its association with future drug use (NSDUH, 2003) and severe neurological/cognitive deficits (Filley, 2004). Many of these products (ie, spray paint, glue, etc.) including toluene and the abuse of pure toluene solvent, has been reported (Flanagan and Ives, 1994). Although overall drug use by teenagers has declined since 1998, inhalant use has increased (NSDUH, 2003). Inhalant use begins in preadolescence and continues well into adulthood (Rosenberg et al, 2002; NSDUH, 2003; Wu and Ringwalt, 2006; Cairney et al, 2005). Dopaminergic afferents arising from the ventral tegmental area (VTA) and projecting to the nucleus accumbens (ACB) are crucial elements in the neural circuits that mediate arousal, motivation, and reinforcement (Wise,

*Correspondence: AC Riegel, Vollum Institute, Oregon Health \& Sciences University, 3 8 I SW Sam Jackson Park Road, Mail Stop L474, Portland, OR 85724-5050, USA, Tel: + I 503494 4723, Fax: + I 503 494 6972, E-mail: Riegela@OHSU.edu

${ }^{4}$ These authors contributed equally to this work.

Received 24 May 2006; revised and ; accepted 6 October 2006
2002). Increased dopamine (DA) neurotransmission within this mesoaccumbal pathway mediates the reinforcing and psychomotor stimulant effects of drugs of abuse (Wise, 2002).

In experimental animals, toluene inhalation produces reinforcing effects (Bespalov et al, 2003; Blokhina et al, 2004; Funada et al, 2002; Weiss et al, 1979; Lee et al, 2006) and stimulates locomotor activity (Bowen, 2006; Riegel et al, 2003). Depletion of DA in the ACB attenuates this latter effect (Riegel et al, 2003). Toluene also induces c-FOS activation in both the VTA and ACB (Lo and Chen, 2005), and increases the firing and bursting of VTA DA neurons in vivo (Riegel and French, 1999a). Although acute toluene exposure increases TTX-sensitive DA release in the dorsal striatum (Stengard et al, 1994), similar effects have not been reported in the ACB (Kondo et al, 1995; Gerasimov et al, 2002b). Therefore, some investigators have concluded that a DA-independent (Spanagel and Weiss, 1999) or an, as yet, undetermined (Hyman and Malenka, 2001) mechanism mediates the actions of toluene. Such conclusions, if incorrect, may confound future work seeking to identify the mechanisms underlying toluene abuse and hamper the development of 
prevention strategies for toluene addiction (Beyer et al, 2001; Schiffer et al, 2006).

DA neurons are spontaneously active (Grace and Bunney, 1983) and their increased action potential firing stimulates DA release in the ACB (Wise, 2002). DA firing is influenced also by multiple mediators including various trans-synaptic inputs, local (GABAergic) interneurons, and somatodendritic DA released from VTA DA neurons (Adell and Artigas, 2004; Marinelli et al, 2006; Beckstead et al, 2004). Therefore, toluene may influence one or more neurotransmitter systems and the effects observed may vary depending upon the treatment regimen employed and the region or subregion examined. Indeed, the VTA is a heterogeneous structure composed of DA and non-DA (ie, $\gamma$-GABA) neurons (Ikemoto and Wise, 2004; Van Bockstaele and Pickel, 1995). Furthermore, recent work has shown that infusion of ethanol and other drugs into the posterior VTA elicits positive reinforcing effects, whereas anterior VTA infusion does not (Zangen et al, 2006; Rodd et al, 2004b; Ikemoto and Wise, 2004). Previous studies investigating toluene did not determine where toluene acts to alter the activity of midbrain DA neurons, and if these changes are sufficient to increase DA release in the ACB (Riegel and French, 1999a).

The present studies determined whether in vivo behaviorally relevant concentrations of toluene directly stimulate mesoaccumbal neurotransmission by a direct activation of VTA DA neurons. In vitro brain-slice experiments revealed that toluene displays anatomical specificity for VTA DA neurons that persists in treatments that reduce synaptic transmission and during longer, escalating exposures designed to emulate 'huffing'. Dual-probe microdialysis studies in awake animals revealed that perfusion of toluene into the VTA increases extracellular DA concentrations in both the VTA and distal ACB. Parts of this data have been presented previously in preliminary form (Riegel and French, 2002).

\section{METHODS}

\section{Toluene}

A stock solution of toluene in polyoxyethylene-sorbitan mono-oleate (Tween-80, final concentration $0.02 \%$ ) was prepared immediately before use with care taken to avoid any solvent loss. For electrophysiological recordings, the stock solution was diluted in oxygenated aCSF (see below) and delivered $(2 \mathrm{ml} / \mathrm{min})$ to the recording chamber $\left(35^{\circ} \mathrm{C}\right)$ by a gravity-feed (plasticizer-free) perfusion system. Toluene was bath applied using two separate protocols. In single applications, each concentration of toluene was applied to the bath for $3 \mathrm{~min}$ to determine reversibility. Existing studies indicate that inhalant abuse is characterized by a rapid intoxication (Meredith et al, 1989) and a related steep rise in brain toluene concentrations (Gerasimov et al, 2002a; Ameno et al, 1992; Kishi et al, 1988). Thus, as with other drugs (Balster and Schuster, 1973), the abuse liability of toluene may be affected by pharmacokinetic properties (Gerasimov et al, 2002a; Lammers et al, 2005) and supplemental 'huffs' may be required to preserve the 'high' reported by users (NSDUH, 2003). Therefore, to better model these conditions, a staircase paradigm was employed.
In this paradigm, escalating concentrations of toluene (seven concentrations at $3 \mathrm{~min} /$ concentration) were applied to the bath and the total duration of toluene exposure was increased $(21 \mathrm{~min})$. Concentrations of toluene in perfusate samples taken from the recording chamber were determined by gas chromatograph (Riegel and French, 1999a) and were adjusted to match in vivo concentrations $(4-79 \mu \mathrm{g} /$ $\mathrm{ml}$ ) observed in the blood of rodents (Riegel and French, 1999a) and humans exposed to toluene (Garriott et al, 1981). The drug reached the recording chamber in $\sim 30 \mathrm{~s}$, and the fluid in the chamber completely turned over in $3 \mathrm{~min}$.

For microdialysis, known aliquots of the toluene stock solution were diluted in aCSF and sealed immediately just before reverse-dialysis. Data generated under conditions similar to those of the present study have shown that $10-30 \%$ of the drug concentration in the perfusion buffer reaches brain tissue surrounding the dialysis probe (Yim and Gonzales, 2000; Gonzales et al, 1998). Thus, perfusate concentrations of toluene $(1,3,10 \mathrm{mM})$ are expected to generate in situ concentrations of $0.1,0.3$, and $1 \mathrm{mM}$, which are in accord with the in vitro concentrations employed $(23-822 \mu \mathrm{M})$ and previous in vivo studies (for a discussion see Riegel et al, 2003).

\section{In Vitro Extracellular Electrophysiology}

Slice preparation. Brain slices were prepared from male Sprague-Dawley rats (PD 19-40) according to protocols approved by the University of Arizona IACUC (Wang and French, 1993b). Control experiments in brain slices prepared from older male Sprague-Dawley rats (PD 60) showed analogous (see below) toluene-induced changes in firing $(n=9$, data not shown). Coronal slices $(400 \mu \mathrm{m})$ containing the VTA were incubated in oxygenated aCSF composed of (in mM) $124 \mathrm{NaCl}, 2.5 \mathrm{KCl}, 1.25 \mathrm{KH}_{2} \mathrm{PO}_{4}, 2.4$ $\mathrm{MgSO}_{4}, 2.5 \mathrm{CaCl}_{2}, 25.7 \mathrm{NaHCO}_{3}$, and $10 \mathrm{D}$-glucose. Where indicated, aCSF was altered by lowering $\mathrm{Ca}^{2+}$ and increasing $\mathrm{Mg}^{2+}$ to either $0.5 \mathrm{mM} \mathrm{Ca}^{2+} / 10 \mathrm{mM} \mathrm{Mg}^{2+}$ (Media-1) or $0.25 \mathrm{mM} \mathrm{Ca}^{2+} / 7.25 \mathrm{mM} \mathrm{Mg}^{2+}$ (Media-2). Flow rates were kept at $2 \mathrm{ml} / \mathrm{min}$ to insure adequate infusion of the altered media, consistent with previous published studies (Bondy and Harrington, 1979; Washio and Inouye, 1978; Alderdice and Volle, 1978; Scholfied, 1981). Incubation with such media for 5 min or greater has been shown to block synaptic transmission (Bondy and Harrington, 1979; Washio and Inouye, 1978; Alderdice and Volle, 1978; Scholfied, 1981; Hutter and Kostial, 1954). Extracellular electrophysiological recordings were made with glass microelectrodes filled with a solution of $2 \%$ pontamine sky-blue in $0.5 \mathrm{M}$ sodium acetate (Yin and French, 2000). Action potential signals were amplified, and filtered $(1-10 \mathrm{kHz}$ ) (Wang and French, 1993a; Marinelli et al, 2006).

Recordings. Recording sites were found with a dissection microscope and confirmed histologically post hoc (see below: 'Localization of recording sites and microdialysis probes'). All locations were anatomically differentiated by reference to the rat atlas (Paxinos and Watson, 1988). VTA neurons were identified according to conventional pharmacological and electrophysiological criteria (Grace and Bunney, 1983; Grace and Bunney, 1984; Johnson and North, 
1992; Cameron et al, 1997; Marinelli et al, 2006). DA neurons possess: (1) bi- or tri-phasic action potentials with a somatodendritic notch, (2) action potential lasting $>2 \mathrm{~ms}$, (3) $\sim 0.5 \mathrm{~Hz}$ firing rates, (4) inhibition to DA $(50-100 \mu \mathrm{M})$, and (5) insensitivity to 5-HT $(60 \mu \mathrm{M})$. Non-DA (type-II) neurons possess: (1) biphasic positive-negative action potentials lacking an S-D notch, (2) action potential lasting $<2 \mathrm{~ms}$, (3) $1-2 \mathrm{~Hz}$ firing rates, and (4) insensitivity to inhibition by DA $(50-100 \mu \mathrm{M})$ and $5-\mathrm{HT}(60 \mu \mathrm{M})$. Non-DA (type-III) neurons displayed: (1) positive-negative action potentials lacking a somatodendritic notch, (2) action potential lasting $>2 \mathrm{~ms}$, (3) $\sim 1.5-2 \mathrm{~Hz}$ firing rates, and (4) inhibition to DA $(50-100 \mu \mathrm{M})$ and 5-HT $(60 \mu \mathrm{M})$. Consistent with previous electrophysiological studies, neurons in the interpeduncular nucleus (IPN) were classified by anatomical location (Lena et al, 1993; Takagi, 1984) and DA neurons in the retrorubral field (RRF) were identified by electrophysiological/pharmacological criteria analogous to those used for VTA DA neurons (Deutch et al, 1988). The identification of neurons in the rostral interstitial nucleus (RIN) was based upon post hoc histological analysis (below).

The duration of inactivation was defined as an episode of reduced action potential amplitude, below noise level, which sometimes occurred immediately after a period of pronounced neuronal excitation. Although the reversibility of toluene's actions permitted multiple challenges, only one cell was recorded from each brain slice.

\section{In Vivo Microdialysis}

Surgery. Male Sprague-Dawley rats (PD 70-80) were anesthetized with equithesin (1\% pentobarbital, $2 \%$ magnesium sulfate, $4 \%$ chloral hydrate, $42 \%$ propyleneglycol, $11 \%$ ethanol, $3 \mathrm{ml} / \mathrm{kg}$ i.p.). Microdialysis guide cannulae (CMA/11, CMA microdialysis, North Chelmsford, MA) were inserted stereotaxically (David Kopf instruments, Topanga, CA) and secured to the skull using stainless-steel screws and dental acrylic. Membrane probe length (VTA: $1 \mathrm{~mm}$; ACB: $2 \mathrm{~mm}$ ) was adjusted for stereotaxic location (VTA: AP -5.6, $L-0.4, V-7.8$; ACB: AP + 1.7, $L-1.4, V-6.4)$, where AP, $L$, and, $V$ denote $\mathrm{mm}$ from bregma (Paxinos and Watson, 1988). After surgery, the animals were housed individually and allowed to recover for 2-4 days before experiments were started.

Microdialysis. Microdialysis was performed as described previously (Zapata and Shippenberg, 2005). The evening before the experiment, probes were inserted into the guide cannulae connected to a perfusion system consisting of $1 \mathrm{ml}$ gastight syringes mounted on microdialysis pumps (CMA/ 102) and fitted with FEP tubing (CMA microdialysis) connecting the probes through dual-channel, quartz-lined, low-resistance swivels. Probes were perfused overnight $(0.3 \mu \mathrm{l} / \mathrm{min})$ and $1 \mathrm{~h}$ before experiments $(1 \mu \mathrm{l} / \mathrm{min})$ with aCSF (in mM: $145 \mathrm{NaCl}, 2.8 \mathrm{KCl}, 1.2 \mathrm{CaCl}_{2}, 1.2 \mathrm{MgCl}_{2}$, 0.25 ascorbic acid, 5.4 D-glucose, $\mathrm{pH}$ 6.5-7.0 adjusted with $\mathrm{NaOH}$ ). During experiments, the VTA superfusate alternated between aCSF, vehicle (Tween-80, final concentration in aCSF $0.02 \%)$, or toluene $(1,3$, and $10 \mathrm{mM} ; 1 \mathrm{~h} /$ concentration). Dialysis fractions were collected every $15 \mathrm{~min}$, frozen $\left(-80^{\circ} \mathrm{C}\right)$, and analyzed for DA content using HPLC-electrochemical detection within $48 \mathrm{~h}$ (Zapata and
Shippenberg, 2005). Dialysate DA concentrations were quantified using an external standard curve. The detection limit of DA in dialysate was $0.3 \mathrm{nM}$.

\section{Localization of Recording Sites and Microdialysis Probes}

The anterior ( -5.2 to $-5.6 \mathrm{~mm}$ posterior to bregma) and posterior ( -5.6 to $-6.04 \mathrm{~mm}$ posterior to bregma) divisions of the VTA were defined as in other studies (Rodd et al, 2005; Zangen et al, 2006; Ikemoto and Wise, 2004; Carlezon et al, 2000; Carlezon and Nestler, 2002; Rodd-Henricks et al, 2000). For electrophysiology, recording sites were confirmed by iontophoresis of pontamine sky-blue dye at experiment completion (Wang and French, 1993a). Then, as described elsewhere (Johnson et al, 1996), brain slices were resectioned $(5-10 \mu \mathrm{m})$, stained with cresyl violet, and examined by light microscopy. Microdialysis probe placement was confirmed after brains were removed, frozen, and sectioned on a cryostat $(30 \mu \mathrm{m})$ as previously described (Zapata and Shippenberg, 2005). Only when probe location was confirmed in both the VTA and ACB (Paxinos and Watson, 1988), was data from that animal included for further analysis.

\section{Data Analysis}

For electrophysiology, only one neuron per slice was tested. Changes in neuron firing rates are expressed as a change from baseline $(\mathrm{Hz})$. Significant differences between treatments were determined by a Student's paired $t$-test. All depicted action potential waveforms are averaged $(\geqslant 4$ spikes/trace). For microdialysis, basal DA levels in dialysate were determined in each animal and represent the average of four samples collected before vehicle perfusion and toluene exposure. For each concentration of toluene, four consecutive $15 \mathrm{~min}$ dialysate samples were obtained. The averaged values at each toluene concentration were compared to the effect of vehicle. Statistical significance was determined using a repeated measure one-way ANOVA and the Newman-Keuls test for post hoc comparisons.

\section{Drugs and Reagents}

Toluene (analytical grade), benzene (reagent grade), and carbon disulfide (reagent grade) were purchased from Fischer Scientific (Tustin, CA). DA and serotonin were purchased from Sigma Chemicals (St Louis, MO) and baclofen from RBI (Natick, MA).

\section{RESULTS}

\section{In Vitro Extracellular Electrophysiology}

Initial experiments using single applications determined whether toluene affects the excitability of VTA DA neurons in an isolated brain slice preparation. Short $3 \mathrm{~min}$ applications of toluene stimulated VTA DA neurons. In all cases, the increase in firing was concentration-dependent and firing rates returned to baseline upon washout (Figure 1a) (maximum $3.4 \pm 0.3 \mathrm{~Hz}$ above baseline; $n=17 ; p<0.05$, data not shown). The maximum increase in firing was greater in 
the anterior VTA (Figure 1d: $4.6 \pm 0.4 \mathrm{~Hz}$ above baseline; $n=7$ ), than the posterior VTA (Figure 1d: $2.8 \pm 0.3 \mathrm{~Hz}$ above baseline; $n=10 ; p<0.01)$. These in situ results resembled previous in vivo studies, with respect to both the basal properties of DA neurons (Table 1) and the reversible, toluene-induced increase in firing (Riegel and French, 1999a). In non-DA neurons, toluene stimulated the firing of type-II (Figure $1 \mathrm{~b} ; n=5$ ) and type-III cells $(n=7)$ (data not shown, but a sample type-III cell is shown in Figure $3 \mathrm{~b}$ ). At both anterior and posterior VTA locations, toluene induced similar increases in non-DA neuron firing. So, the data were grouped (Figure 1d: maximum $3.21 \pm 0.63 \mathrm{~Hz}$ above baseline; $n=12$ ). The stimulation of non-DA cells in vitro differs from the inhibition of firing previously observed in vivo (Riegel and French, 1999b), and may reflect the loss of monosynaptic glutamate inputs to neurons in a slice preparation (Tzschentke, 2001).

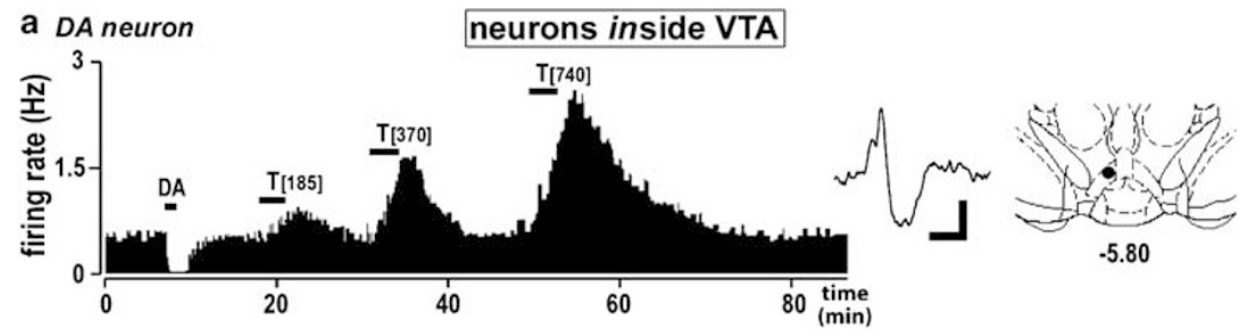

b non-DA neuron
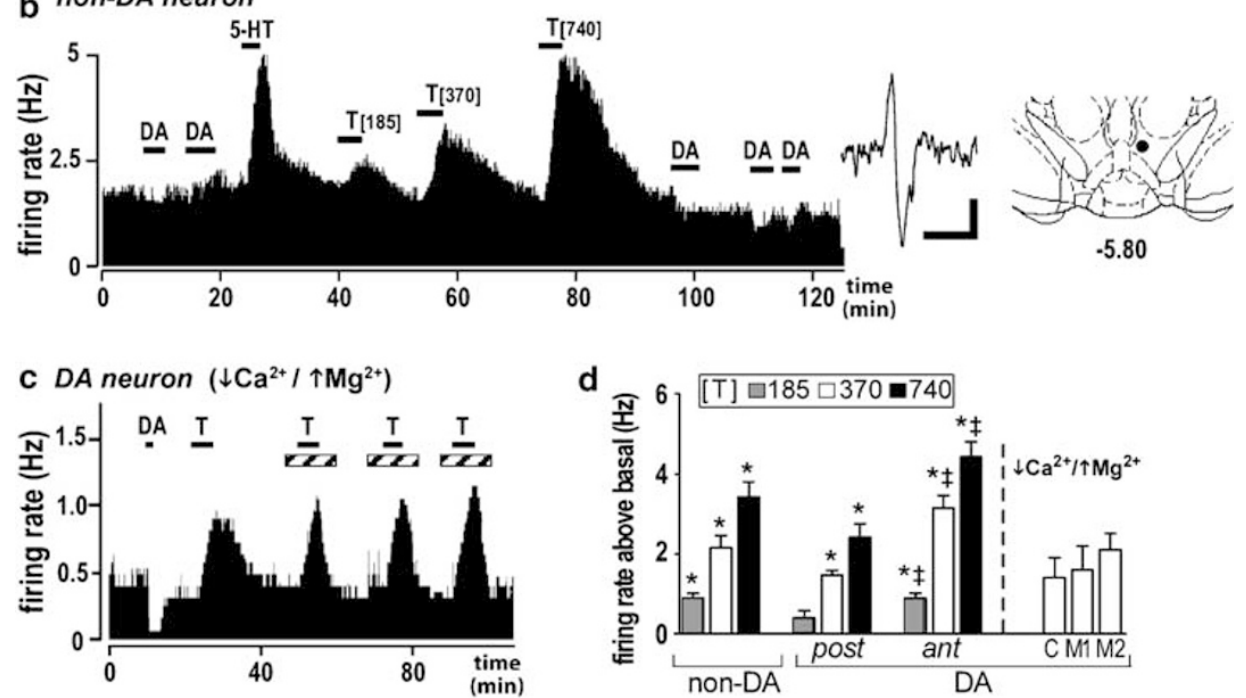

Figure I Toluene stimulates VTA neurons in vitro (single applications). Sample ratemeter histograms of a VTA (a) DA and (b) non-DA neuron during toluene (3 min/concentration). Insets on the right show matching action potential waveforms (calibration: I ms \& $0.2 \mathrm{mV}$ ) and far right, the anatomical location of recording electrode (number is $\mathrm{mm}$ posterior from bregma). Numbers above bars in (a) and (b) indicate concentration ( $\mu \mathrm{M})$ of drugs ( $\mathrm{T}$ : toluene; DA: 50-100 $\mathrm{M}$ DA; 5-HT: $60 \mu \mathrm{M}$ serotonin). (c) Toluene application (black bar, $370 \mu \mathrm{M}$ ) stimulates firing in a VTA DA neuron, even when inhibiting synaptic transmission by perfusion with high $\mathrm{Mg}^{2+}$, low $\mathrm{Ca}^{2+}$ aCSF (hatched bars). (d) Summary of the toluene-induced changes in firing of VTA non-DA $(n=12)$ and DA neurons in the anterior (ant) VTA $(n=10)$ or posterior (post) VTA $(n=7)$. White bars on far right summarize results of high $\mathrm{Mg}^{2+}$, low $\mathrm{Ca}^{2+}$ aCSF media (C: control, MI: media- I, M2: media-2). Error bars signify SEM. * Signifies significance at $p<0.05$ vs vehicle; ${ }^{\ddagger}$ signifies significance at $p<0.05$ vs posterior.

Table I Properties of Different Midbrain Neurons

Change in firing (\%) from baseline in the presence of:

Neuron (n) Challenges (n) Brain region Neuron subtype AP duration (ms) Basal firing (Hz)

$60 \mu \mathrm{M} 5-\mathrm{HT} \quad 50-100 \mu \mathrm{M}$ DA

\begin{tabular}{|c|c|c|c|c|c|c|c|}
\hline 43 & 247 & VTA & Type I DA & $2.70 \pm 0.32$ & $0.56 \pm 0.12$ & $14.6 \pm 1.7$ & $-96.4 \pm 3.1$ \\
\hline | | & 63 & VTA & Type II non-DA & $1.80 \pm 0.17$ & $1.90 \pm 0.11$ & $8.4 \pm 4.1$ & $-11.7 \pm 2.9$ \\
\hline 13 & 69 & VTA & Type III non-DA & $2.50 \pm 0.19$ & $3.10 \pm 0.10$ & $-94.1 \pm 4.2$ & $-96.7 \pm 1.2$ \\
\hline 6 & 24 & $\mathrm{RIN}$ & ND & $1.61 \pm 0.12$ & $3.90 \pm 0.12$ & ND & $9.8 \pm 1.2$ \\
\hline 7 & 29 & IPN & ND & $1.21 \pm 0.12$ & $11.00 \pm 2.70$ & ND & $7.8 \pm 4.4$ \\
\hline
\end{tabular}

VTA, ventral tegmental area; RRF, retrorubral field; RIN, rostral interstitial nucleus; IPN, interpeduncular nucleus. 
To determine whether toluene increased VTA firing by altering neurotransmitter release onto DA cells, we tested a low- $\mathrm{Ca}^{2+}$, high- $\mathrm{Mg}^{2+}$ aCSF media, previously shown to inhibit synaptic transmission (Brodie et al, 1990; Katz, 1970; Katz and Miledi, 1970). The stimulatory properties of toluene $(370 \mu \mathrm{M})$ were still apparent under these conditions (Figure 1c: $370 \mu \mathrm{M}$, single applications). As basal firing rates can vary under low $\mathrm{Ca}^{2+}$ conditions, initial results with toluene in media-1 $\left(0.5 \mathrm{mM} \mathrm{Ca}^{2+} / 10 \mathrm{mM} \mathrm{Mg}^{2+}\right.$; Figure $1 \mathrm{~d}$ : $1.73 \pm 0.86 \mathrm{~Hz}$ above baseline; $n=5)$ were confirmed with experiments in media-2 $\left(0.25 \mathrm{mM} \mathrm{Ca}{ }^{2+} / 7.25 \mathrm{mM} \mathrm{Mg}^{2+}\right.$; Figure 1d: $2.32 \pm 1.01 \mathrm{~Hz}$ above baseline; $n=5)$. The magnitude of the toluene-induced increase in firing did not differ between media (Figure 1d; $p>0.05$, ANOVA), suggesting that toluene directly activates VTA neurons.

To determine if the stimulatory properties of toluene were unique to the VTA, three adjacent midbrain structures were tested using single applications. In the IPN, the basal firing rate was $11.0 \pm 2.70 \mathrm{~Hz}$ (Table 1). Toluene inhibited the firing of neurons in the IPN (Figure 2a). The response was robust and concentration-dependent (Figure 2d: maximum, $-10.2 \pm 0.71 \mathrm{~Hz}$ below baseline; $n=7)$. However, transient $(<30 \mathrm{~s})$ and concentration-independent increases were also noted in some neurons in the IPN (Figure 2a: $<4 \mathrm{~Hz}, n=2$ ).
In contrast, toluene did not significantly alter neuronal activity in the RRF (Figure 2b) or RIN (Figure 2c) (Figure 2e; maximum, $0.43 \pm 0.39 \mathrm{~Hz}$ above baseline, $n=12 ; p>0.05)$. Basal firing characteristics of neurons in the IPN and RRF are summarized in Table 1, and resemble those reported previously (Takagi, 1984; Deutch et al, 1988). The characteristics of neurons in the RIN are shown (Table 1), although characterization of this region is lacking. Thus, these results demonstrate that behaviorally relevant concentrations of toluene (single applications) selectively stimulate VTA neurons and that the increase in firing is similar in both DA and non-DA neurons.

Behavioral responses to solvents are determined in part by the pattern of exposure (Lammers et al, 2005). Therefore, prolonged in vitro exposures were investigated. Using a staircase paradigm, we observed that cumulative applications of toluene stimulated VTA DA neurons (Figure 3a; $22-823 \mu \mathrm{M}$ ) and non-DA neurons (Figure 3b; 22-633 $\mu \mathrm{M}$ ). The increases in firing were concentration-dependent and reversed upon washout (Figure 3a and b). At DA neurons, the efficacy of toluene did not change as a function of exposure paradigm. Thus, maximal activity under staircase conditions (Figure 3c: $4.07 \pm 0.44 \mathrm{~Hz}$ above baseline at $822 \mu \mathrm{M}$ toluene, first application, $n=21$ ) resembled firing
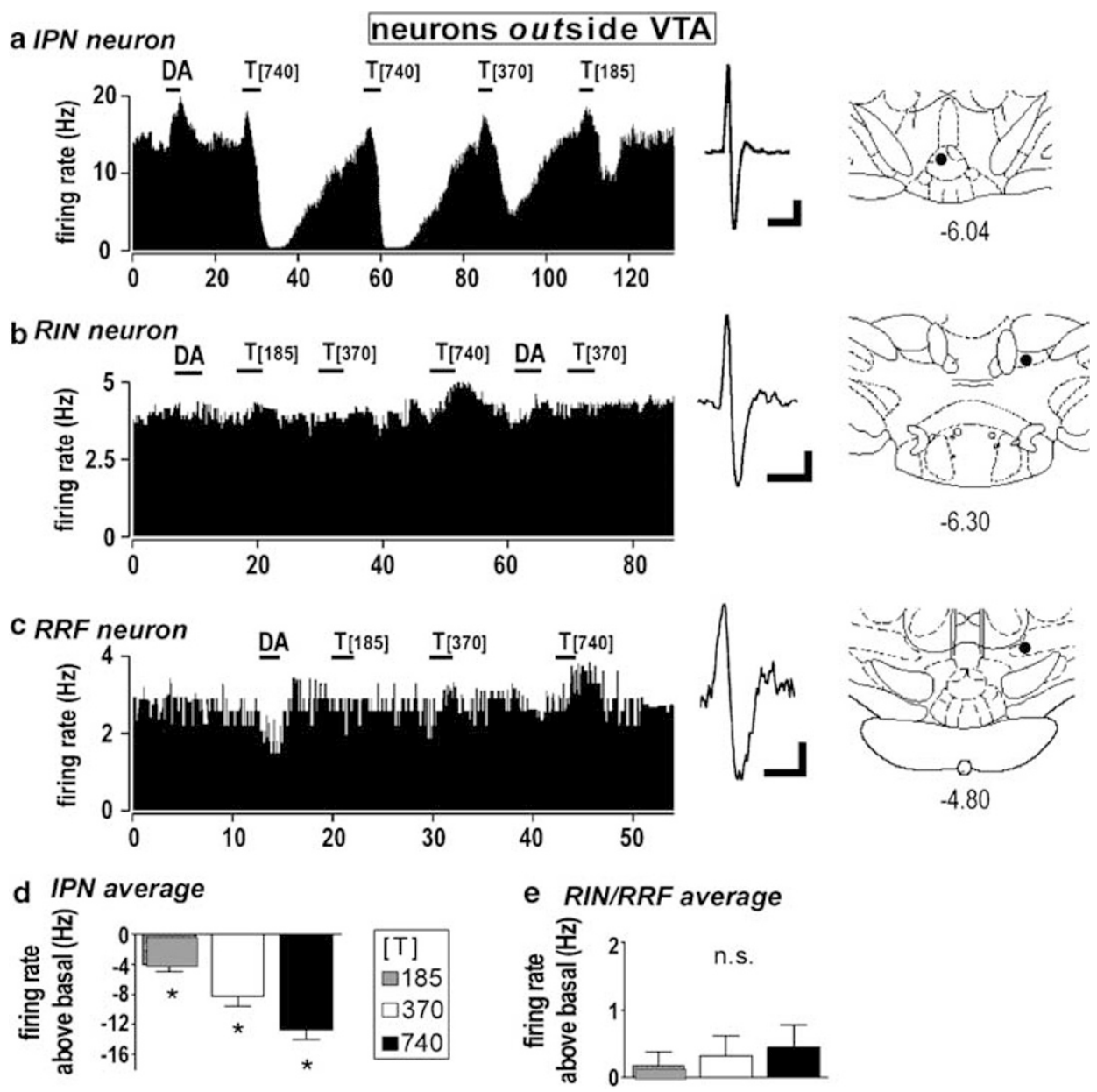

Figure 2 Toluene does not significantly stimulate the in vitro firing in other midbrain regions (single applications). Sample ratemeter histograms of neurons in the IPN (a), RIN (b), and RRF (c). Insets on the right show matching action potential waveforms (calibration: I ms and $0.2 \mathrm{mV}$ ) and on the far right, the anatomical location of recording electrode ( $\mathrm{mm}$ posterior from bregma). (d, e) Summary of the toluene-induced changes in firing of neurons in the IPN $(n=7)(d)$ and both RIN $(n=6)$ and RRF $(n=6)(e)$. *Signifies significance at $p^{*}<0.05$. 


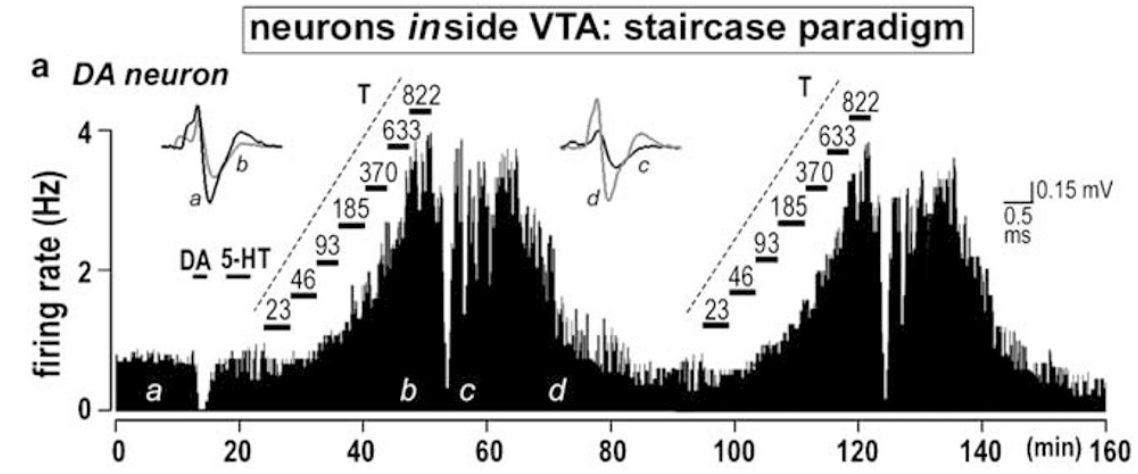

b non-DA neuron $\quad \mathrm{T} 63$
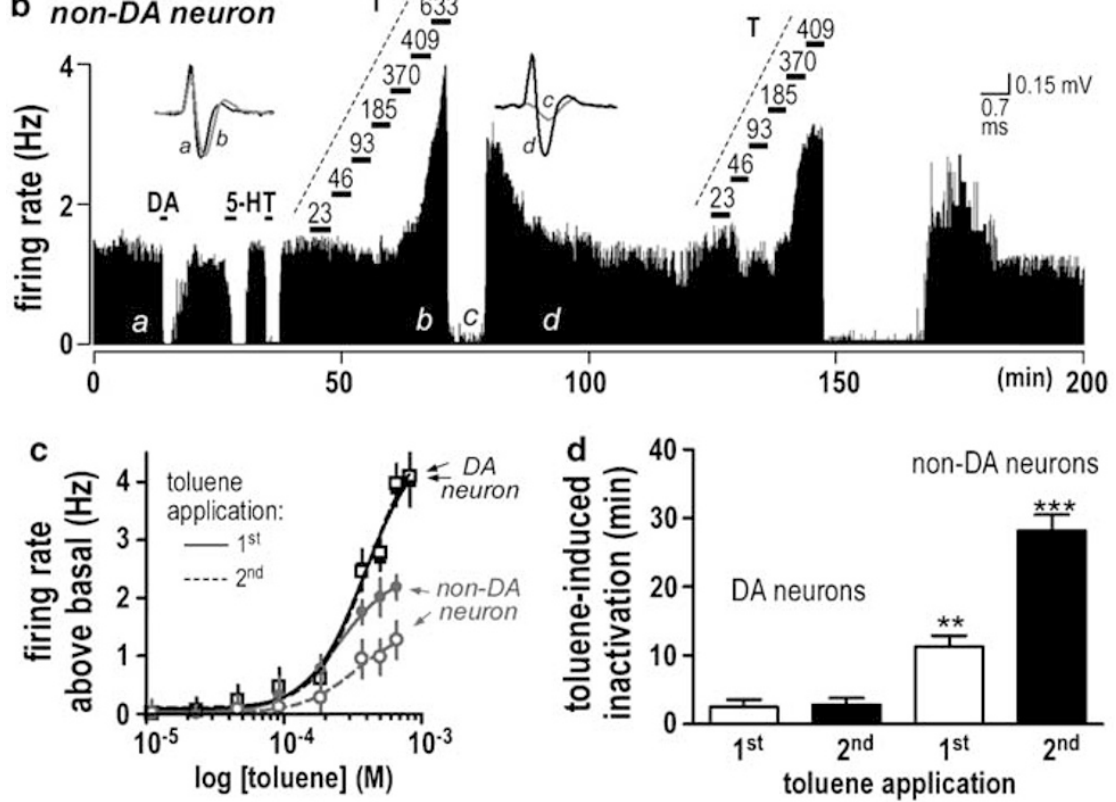

Figure 3 During longer repeat exposures, DA and non-DA neurons in the VTA respond differently to toluene (staircase paradigm). Sample ratemeter histograms of (a) DA and (b) non-DA neurons recorded in vitro during staircase application of toluene (3 min/concentration; seven concentrations). At the highest concentrations of toluene, firing briefly stopped (inactivated) and became undetectable. In (a), repeat applications of toluene generate similar periods of inactivation ( $\sim 4 \mathrm{~min}$ ). In contrast in (b), inactivation lengthened (application- I: $\sim 9 \mathrm{~min}$; application-2: $\sim 29$ min). Insets show action potential waveforms at the times (indicated with letters) in the rate histograms. (c) Concentration-response curves for toluene. (d) Summary graph illustrating the mean duration of inactivity. *** Signifies significance at $p<0.00$ I; ** signifies significance at $p<0.0$ I.

under conditions using single applications (Figure 1d: $3.41 \pm 0.37 \mathrm{~Hz}$ above baseline at $740 \mu \mathrm{M}$ toluene, $n=17)$. In contrast, in non-DA neurons under staircase conditions, the maximal efficacy of toluene declined $\sim 40 \%$ (Figure 3c: $2.19 \pm 0.32 \mathrm{~Hz}$ above baseline; at $633 \mu \mathrm{M}$, first application, $n=9$ ) relative to single applications (Figure 1d: $3.21 \pm 0.63$ above baseline at $740 \mu \mathrm{M}, n=12$ ). The diminished efficacy is unlikely to be owing to tissue accumulation of toluene, because at comparable concentrations, the magnitude of the increase in DA cell firing was similar during both short (single applications: $3 \mathrm{~min}$ ) and long (staircase: $21 \mathrm{~min}$ ) exposures. Furthermore, the attenuation of firing was observed only in non-DA neurons during cumulative staircase conditions. More prolonged staircase exposure to toluene ( $>21 \mathrm{~min}$ ) inactivated VTA DA (Figure 3a) and non-DA (Figure $3 \mathrm{~b}$ ) neurons and briefly limited further firing. As noted in previous studies (Riegel and French, 1999a), this stimulation-induced inactivation was not owing to acute, irreversible cell death, because in all instances, firing recovered to baseline when the perfusion media were replaced with toluene-free aCSF.

With first applications, toluene inactivated non-DA neurons 2-3 times longer than DA neurons (Figure 3a and b). To investigate if the toluene-induced inactivation of non-DA neurons was additive, the staircase paradigm was reapplied after firing resumed. The efficacy and duration of inactivation during the two repetitive episodes were noted for comparison. In DA neurons (Figure 3a), maximal firing (Figure 3c; episode-1: $4.00 \pm 0.42 \mathrm{~Hz}$ above baseline, $n=17$; episode-2: $4.09 \pm 0.49 \mathrm{~Hz}$ above baseline, $n=9)$ and periods of inactivity (Figure 3d: episode-1: $2.50 \pm 1.11 \mathrm{~min}, n=17$; episode-2: $2.82 \pm 0.96 \mathrm{~min}, n=9)$ remained the same. In non-DA neurons (Figure $3 \mathrm{~b}$ ), however, maximal efficacy declined (Figure 3c episode-1: $2.2 \pm 0.2 \mathrm{~Hz}$ above baseline, $n=9$; episode-2: $1.3 \pm 0.3 \mathrm{~Hz}$ above baseline, $n=3$ ) and the duration of inactivation increased (Figure 3d; episode-1: $11.3 \pm 1.6 \mathrm{~min}, n=9, p<0.01$; episode- $2: 28.2 \pm 2.3 \mathrm{~min}$, $n=3 ; p<0.001)$. Any assessment of toluene during a third 
episode was not possible, because of the limitation of recording from a single neuron for longer than $2.5 \mathrm{~h}$. Higher concentrations of toluene were not investigated because of the plateauing of neuronal stimulation. The decline in efficacy and increase in the period of inactivation was only observed in non-DA neurons. Toluene $(<1 \mathrm{mM})$ stimulated VTA DA neuron firing repeatedly without a significant decline in efficacy.

\section{In Vivo Microdialysis}

Given these findings, we determined whether toluene can stimulate VTA DA neurons directly in vivo, and if so, whether this effect is sufficient to increase mesoaccumbal DA release. Dual-probe microdialysis was used to measure concentrations of somatodendritic DA release in the VTA, an indirect marker of VTA DA neuron activity, and DA released from DA terminals in the ACB.

$D A$ release in the VTA. Toluene was infused directly into the VTA by reverse dialysis at concentrations of 1,3 , or $10 \mathrm{mM}$ (see Methods). In the VTA, infusion of vehicle resulted in a non significant shift $(<15 \%)$ in basal dialysate DA concentrations (Figure 4a: $0.67 \pm 0.09 \mathrm{nM} ; n=9$ ). In contrast, infusion of toluene increased concentrations of somatodendritic VTA-DA (Figure $4 \mathrm{a}$ and b: $\mathrm{F}_{3,24}=13.21$, $p<0.0001)$. A significant increase was observed in response to 3 and $10 \mathrm{mM}$ toluene (Figure $4 \mathrm{~b} ; p<0.001 v s$ vehicle). Significant increases in VTA DA were observed when toluene was infused into anterior or posterior VTA regions (Figure $4 \mathrm{~b}$; antVTA: $\mathrm{F}_{3,12}=5.376, p=0.014$; post VTA: $\mathrm{F}_{3,9}=8.561, p=0.0055$ ANOVA). The anatomical location of all dialysis probes is shown in Figure 5.

$D A$ release in the $A C B$. The basal concentration of $A C B$ DA in dialysate was $1.82 \pm 0.43 \mathrm{nM}$. DA concentrations in the ACB did not change following intra-VTA vehicle perfusion. However, reverse-dialysis of toluene into the VTA significantly increased DA levels in the ACB (Figure $4 \mathrm{c}$ and $\mathrm{d}$; $n=11, \quad \mathrm{~F}_{3,43}=3.561, \quad p=0.026$, ANOVA). All tolueneinduced increases in DA reversed within $60 \mathrm{~min}$. The ACB-DA increases were significant, when toluene was infused into the posterior VTA (Figure $4 \mathrm{~d} ; \mathrm{F}_{3,18}=4.772$, $p=0.013$, ANOVA), but not the anterior VTA (Figure $4 \mathrm{c}$ and $\mathrm{d} ; \mathrm{F}_{3,9}=1.613, p=0.250$, ANOVA). This topographical selectivity (posterior VTA $v s$ anterior VTA) parallels that previously observed in behavioral studies in which microinjection techniques were used to assess the effects of other drugs of abuse including both alcohol, and cannabinoids (Zangen et al, 2006; Zangen et al, 2002; Ikemoto and Wise, 2004; Rodd-Henricks et al, 2000, 2002; Rodd et al, 2005). To confirm functional connectivity between the posterior VTA and ACB probe placements, baclofen was infused into the VTA and DA levels after toluene washout and ACB DA levels were determined (Westerink et al, 1996). Baclofen produced a robust decline in ACB DA concentrations ( $35 \pm 8 \%$ of vehicle; $n=11$; data not shown). Perfusion of toluene into regions anterior $(n=5)$, dorsal $(n=7)$, lateral $(n=2)$, or ventral $(n=2)$ to the VTA failed to alter ACB-DA (Figure $4 \mathrm{e}$ and $\mathrm{f}$ ) demonstrating the regional selectivity of this effect. Collectively, these data show that the effects of toluene on ACB-DA levels are specific to the posterior VTA.

\section{DISCUSSION}

The present results indicate that toluene directly stimulates DA cell firing, thereby facilitating DA release in the ACB. Dopaminergic innervation of the ACB is a key substrate for the reinforcing effects of other drugs of abuse (Wise, 2002). Nevertheless, despite intensive study, the neural substrates mediating the CNS actions of toluene have remained elusive. Previous behavioral studies indicated that the locomotor activating effects of toluene require intact mesoaccumbal DA transmission (Riegel et al, 2003). Moreover, toluene increases the activity of VTA DA neurons in vivo (Riegel and French, 1999a). To date, however, it remained unclear whether toluene stimulated these neurons by direct actions on neurons within the VTA and if such activation was sufficient to increase DA release from distal DA terminals in the ACB.

\section{Toluene Stimulates VTA Neurons, Leading to DA Release in the ACB}

Our data support the premise that toluene-containing inhalants activate mesoaccumbal neurotransmission via direct actions on VTA DA neurons. First, toluene stimulated DA neurons in the VTA slice, a preparation in which transynaptic inputs to DA cells are severed (Tzschentke, 2001). Similar effects were observed in slices incubated in aCSF containing low $\mathrm{Ca}^{2+} /$ high $\mathrm{Mg}^{2+}$, conditions in which synaptic transmission is inhibited (Katz, 1970; Katz and Miledi, 1970). Identical media were used previously to study the site of action for other drugs of abuse (Brodie et al, 1990; Sanghera et al, 1984; Trulson et al, 1987) including toluene (in other regions) (Magnusson et al, 1998). These findings suggest that toluene increases DA neuronal activity post-synaptically and independently of afferent input.

Second, in vivo microdialysis showed that direct intraVTA perfusion of toluene enhanced DA concentrations in the VTA and ACB. As VTA DA neuron cell bodies are the only known source of DA in this region (Adell and Artigas, 2004), the former effect most likely reflects the welldescribed increase in somatodendritic DA release that occurs as a consequence of increased firing of DA neurons (Adell and Artigas, 2004). Other drugs of abuse also increase somatodendritic DA release (Adell and Artigas, 2004). Work, however, from several laboratories has shown that the VTA is functionally heterogeneous (Ikemoto and Wise, 2004; Ford et al, 2006). Experimental animals will work to obtain infusions of ethanol, opiates, cannabinoids, or psychostimulants into the posterior VTA, whereas infusions into the anterior VTA are without effect (Rodd-Henricks et al, 2000, 2002; Rodd et al, 2005; Rodd et al, 2004b; Zangen et al, 2006). Interestingly and consistent with this heterogeneity, microdialysis revealed that toluene was more effective in increasing ACB-DA concentrations when infused directly into the posterior than in the anterior VTA.

Third, the effects of toluene were anatomically specific. Unlike VTA DA cells, bath application of toluene did not alter DA neuronal firing in the RRF or RIN. Furthermore, firing of GABAergic neurons in the IPN was inhibited. Similarly, reverse-dialysis of toluene into regions adjacent to the VTA did not alter ACB-DA levels. Anterior VTA perfusion of toluene failed to change ACB-DA, a finding 

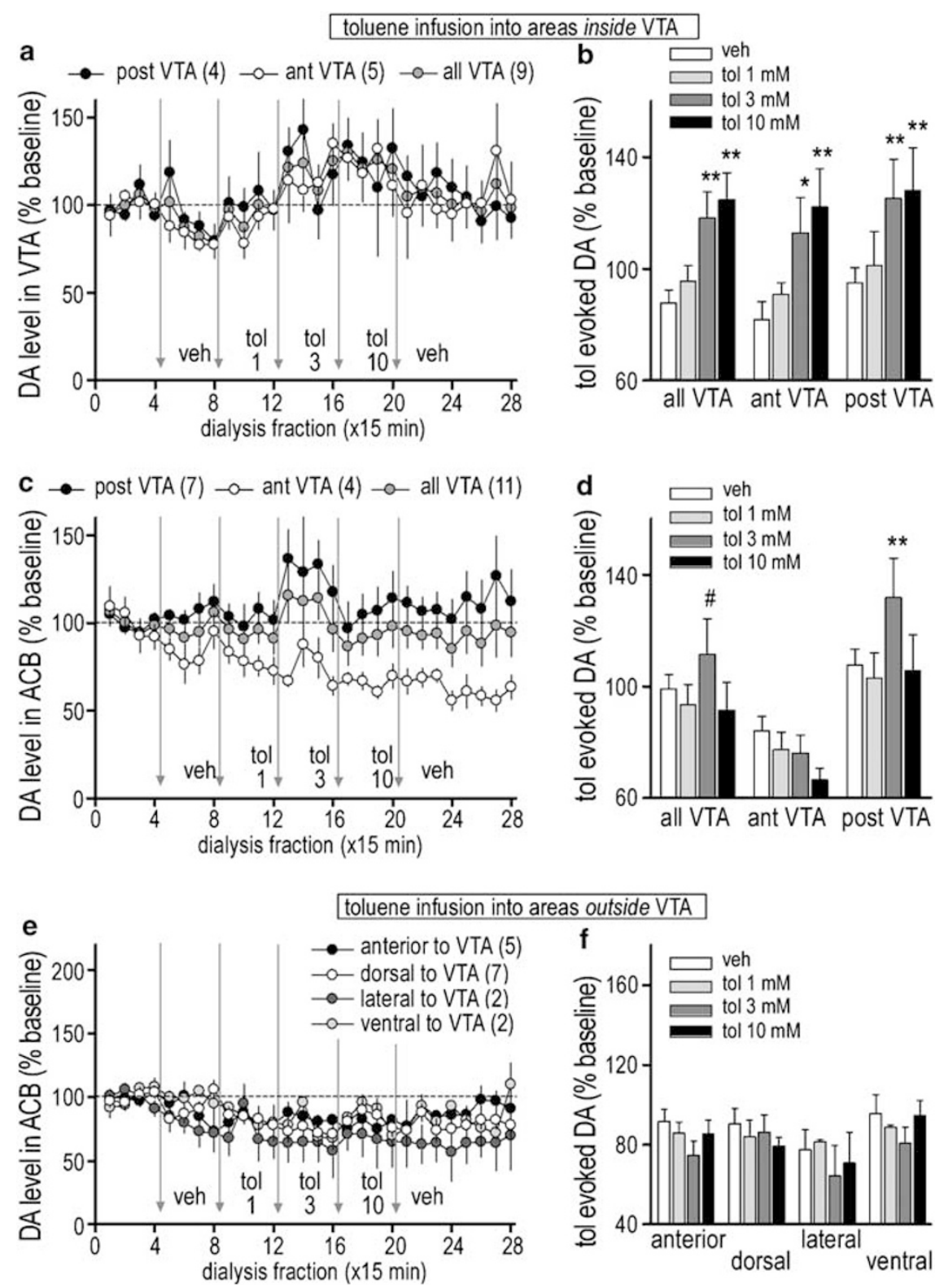

Figure 4 In vivo, the direct infusion of toluene into the VTA increases DA in the VTA and ACB; infusion of toluene outside the VTA does not. Time courses illustrate changes in mean extracellular concentrations of DA dialysate concentrations in the VTA (a) and ACB (c, e). Bar graphs summarize mean changes in DA dialysate concentrations in the VTA (b) and ACB (d, f). (a-d) Changes in DA dialysate following vehicle or toluene infusion inside the VTA. (e, f) Changes in DA dialysate in the ACB following vehicle or toluene infusion outside the VTA. Numbers in parentheses signify the number of animals. Data are the mean and error bars signify SEM. The symbols *, **, and \# signify significance at $p<0.05, p<0.02$, and $p=0.07$, respectively.

consistent with anatomical studies showing that most DA neurons in this region do not innervate the ACB (Westerink et al, 1998; Tzschentke, 2001; Brog et al, 1993). However, there is an apparent trend to a delayed response, the magnitude of which may have been masked by a downward baseline drift in this experimental group. This delayed response may reflect diffusion of toluene from the probe to more posterior VTA regions. The toluene-induced stimulation of anterior VTA DA neurons may be related to the reported toluene-induced increase in DA release in the prefrontal cortex (Gerasimov et al, 2002b). Taken together, these findings indicate that by stimulating posterior VTA DA cells, toluene increases extracellular DA concentrations in the distal ACB.

\section{Concentration Dependence and Neurobehavioral Implications}

Toluene is rapidly absorbed, distributed, and eliminated from brain tissue (Gerasimov et al, 2002a; Kishi et al, 1988). Behavioral effects of toluene depend on both the brain concentrations and the pattern of exposure (Kishi et al, 1993; Lammers et al, 2005). Although inhalation exposure is relevant to inhalant abuse, the site (or sites) of action can be difficult to interpret. In both of our experimental approaches, toluene was delivered directly to the VTA. The concentrations of toluene employed were those previously shown to be achieved in humans (Garriott et al, 1981) and experimental animals (see discussion in Riegel et al, 2003). 

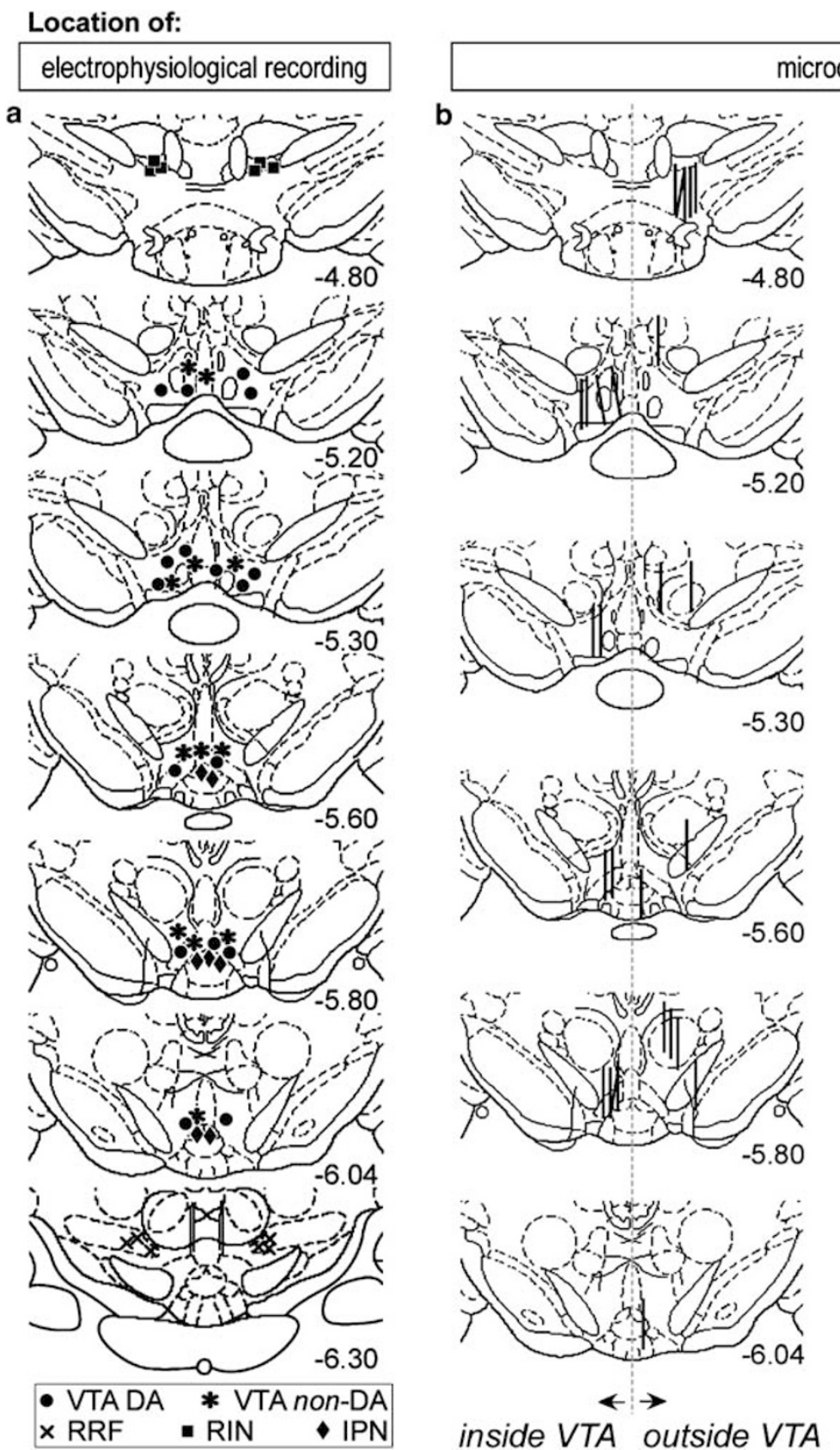

microdialysis probes

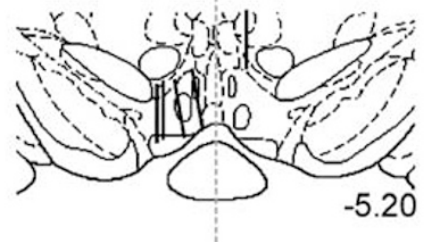

c
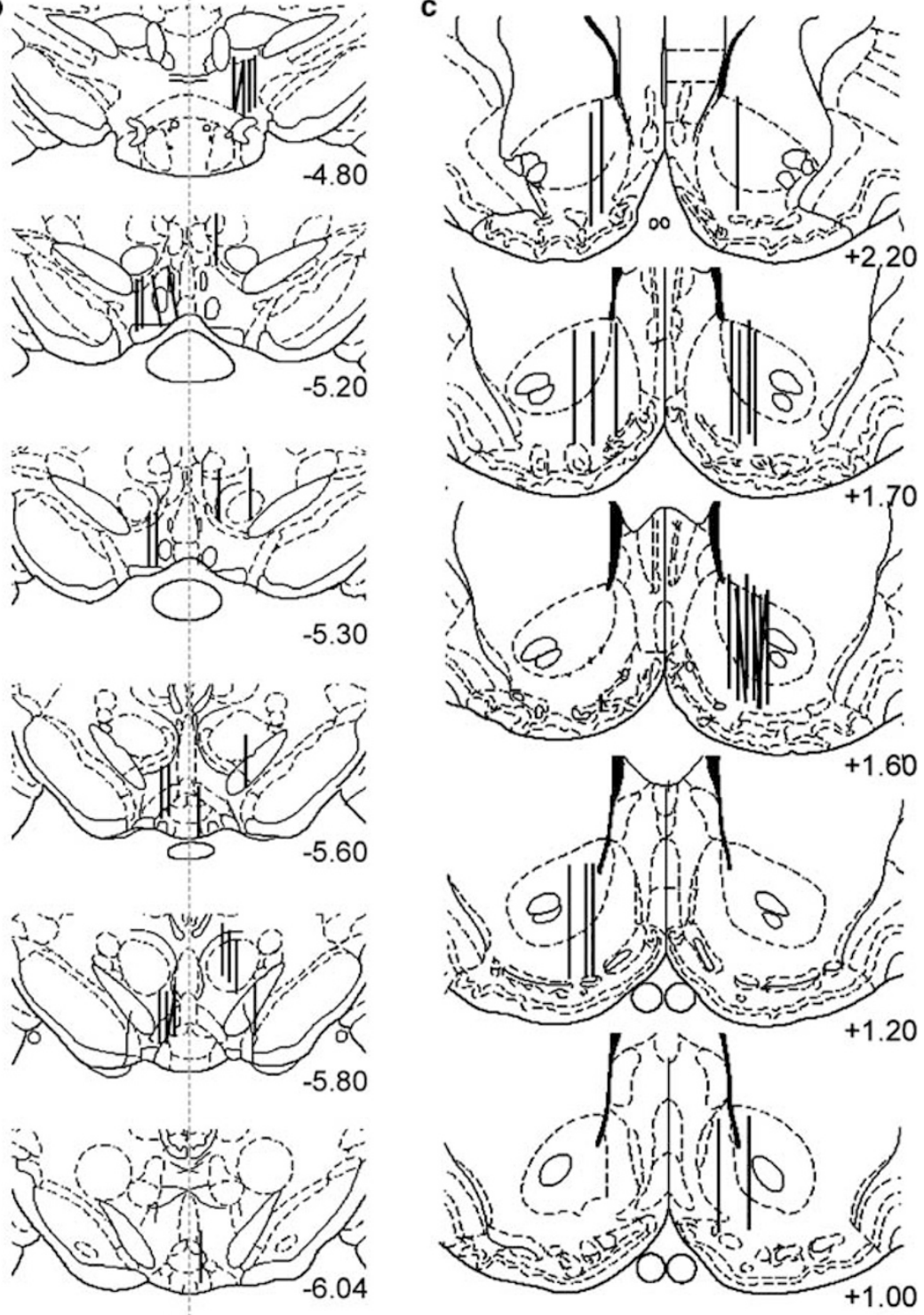

nucleus accumbens

Figure 5 Summary of all anatomical locations for (a) electrophysiological recordings in the midbrain, (b) dialysis probes in the midbrain, and (c) dialysis probes in the ACB. In (b), tracts left of midline represent probe locations of animals with a positive VTA location. Tracts right of midline represent probe locations from animals with a negative VTA location, which served as negative anatomical controls. Numbers on the atlas plate indicate the distance from bregma in mm. Adapted from Paxinos and Watson (1998).

To simulate this exposure pattern in vitro, VTA slices were perfused with repeated, rapidly rising, escalating concentrations of toluene (staircase paradigm). Extracellular recordings preserve action potential firing for long periods of time and are correlated with DA release in the ACB (Marinelli et al, 2006; Westerink et al, 1996). We observed that VTA firing increased only over a narrow concentration range. At lower concentrations $(<100 \mu \mathrm{M})$, toluene increased DA cell firing rates, but ACB DA concentrations were unaltered. As noted elsewhere (Wise, 2002; Yeomans, 1989), the stimulation of unmyelinated fibers may have been insufficient to detect increased synaptic overflow of DA in distal terminals. At intermediate concentrations, toluene increased both DA neuron firing and DA concentrations in the ACB. As discussed above (see Methods), retro-dialysis results in an estimated 10-fold reduction in drug tissue concentration. Therefore, there is good concordance between the current results and previous in vivo experiments, where blood toluene concentrations of $300 \mu \mathrm{M}$ stimulated VTA DA neurons (Riegel and French, 1999a).

The firing of VTA DA neurons inactivated temporarily when toluene concentrations reached $\sim 1 \mathrm{mM}$. This inactivation persisted until concentrations decreased, and is consistent with previous in vivo inhalation studies showing inactivation of DA neurons when blood toluene 
concentrations exceeded $\sim 900 \mu \mathrm{M}$ (Riegel and French, 1999a). Thus, it is plausible that the lack of toluene-induced DA release in previous in vivo studies results from an inactivation of VTA DA neurons induced by higher toluene concentrations (Kondo et al, 1995; Gerasimov et al, 2002b).

The lack of an accumbal DA response to $10 \mathrm{mM}$ toluene may seem surprising given that this concentration increased extracellular DA concentrations in the VTA (ie, somatodendritic release). The mechanisms mediating the differential effects of the higher toluene concentration on VTA and ACB DA levels are unclear. Importantly, however, DA clearance in the VTA is less efficient than in terminal areas (Cragg and Greenfield, 1997). Thus, DA tissue concentrations may remain elevated even after suppression of cell firing in the VTA. It is known that depolarization inhibits DA transporter function (Sonders et al, 1997). Sustained depolarization by toluene may further inhibit VTA DA uptake resulting in impaired DA clearance in this region and an elevation of VTA DA levels. Interestingly, other organic solvents (eg, ethanol) inhibit DA uptake (Robinson et al, 2005). Therefore, direct effects of toluene on transporter activity cannot be ruled out.

In the staircase paradigm, VTA non-DA neurons were also stimulated. However, unlike DA cells, these neurons displayed an inactivation threshold that became lower with repeated stimulation. Some VTA non-DA cells are GABA projection neurons (Cameron et al, 1997; Van Bockstaele and Pickel, 1995), which innervate striatal cholinergic interneurons (Pickel and Chan, 1990) and cerebellar nuclei (Ikai et al, 1992). Although the functional role of these neurons is not completely understood (Van Bockstaele and Pickel, 1995), their activation by low concentrations of toluene may contribute to TTX-sensitive increases in extracellular levels of GABA in these regions (Stengard and O'Connor, 1994; Stengard et al, 1993) and to decreases in striatal ACh release (Stengard, 1994) during toluene inhalation. Other VTA non-DA cells are GABAergic interneurons (type-II) that tonically inhibit VTA DA neurons in vivo (Johnson and North, 1992). Although the mechanism underlying the shift in the inactivation point remains unclear, increases in the firing activity of DA over GABA neurons would be expected to facilitate mesoaccumbal output.

Finally, regarding the cellular targets, studies in cell expression systems indicate that toluene disrupts the activity of numerous ion channels (Cruz et al, 1998; Bale et al, 2005; Beckstead et al, 2000), $\mathrm{Ca}^{2+}$ signaling (Westerink and Vijverberg, 2002; Westerink et al, 2002; Meulenberg and Vijverberg, 2003), ATPases (CalderonGuzman et al, 2005), and G-proteins (Tsuga et al, 1999; Tsuga and Honma, 2000; Tsuga et al, 2002). Additional studies will be needed to determine if one or more of these mechanisms may be contributing to the toluene-induced excitation of VTA DA neurons.

In conclusion, our results indicate that toluene selectively activates VTA DA neurons projecting to the ACB. They identify a narrow concentration range within which toluene directly stimulates mesoaccumbal neurotransmission. Such findings suggest that previous conclusions, that DAindependent mechanisms underlie the rewarding properties of inhalants, may be premature. Furthermore, given the alarming increase in inhalant abuse among youth (NSDUH,
2003), additional studies examining the interaction of toluene and other inhalants with the mesoaccumbal DA reward pathway are warranted.

\section{ACKNOWLEDGEMENTS}

We thank Drs Karten, Krause, Beckstead, Ford, and Williams for critically reading the manuscript. Support for A Riegel was provided by NIDA T-334180. A Zapata and $\mathrm{T}$ Shippenberg were supported by the National Institute on Drug Abuse, Intramural Research Program.

\section{REFERENCES}

Adell A, Artigas F (2004). The somatodendritic release of dopamine in the ventral tegmental area and its regulation by afferent transmitter systems. Neurosci Biobehavi Revi 28: 415-431.

Alderdice MT, Volle RL (1978). The increase in spontaneous transmitter release produced by beta-bungarotoxin and its modification by inorganic ions. J Pharmacol Exp Ther 205: 58-68.

Ameno K, Kiriu T, Fuke C, Ameno S, Shinohara T, Ijiri I (1992). Regional brain distribution of toluene in rats and in a human autopsy. Arch Toxicol 66: 153-156.

Bale AS, Tu Y, Carpenter-Hyland EP, Chandler LJ, Woodward JJ (2005). Alterations in glutamatergic and gabaergic ion channel activity in hippocampal neurons following exposure to the abused inhalant toluene. Neuroscience 130: 197-206.

Balster RL, Schuster CR (1973). Fixed-interval schedule of cocaine reinforcement: effect of dose and infusion duration. J Exp Anal Behav 20: 119-129.

Beckstead MJ, Grandy DK, Wickman K, Williams JT (2004). Vesicular dopamine release elicits an inhibitory postsynaptic current in midbrain dopamine neurons. Neuron 42: 939-946.

Beckstead MJ, Weiner JL, Eger EI, Gong DH, Mihic SJ (2000). Glycine and gamma-aminobutyric acid(A) receptor function is enhanced by inhaled drugs of abuse. Mol Pharmacol 57: 1199-1205.

Bespalov A, Sukhotina I, Medvedev I, Malyshkin A, Belozertseva I, Balster $\mathrm{R}$ et al (2003). Facilitation of electrical brain selfstimulation behavior by abused solvents. Pharmacol Biochemi Behav 75: 199-208.

Beyer CE, Stafford D, LeSage MG, Glowa JR, Steketee JD (2001). Repeated exposure to inhaled toluene induces behavioral and neurochemical cross-sensitization to cocaine in rats. Psychopharmacology (Berl) 154: 198-204.

Blokhina EA, Dravolina OA, Bespalov AY, Balster RL, Zvartau EE (2004). Intravenous self-administration of abused solvents and anesthetics in mice. Eur J Pharmacol 485: 211-218.

Bondy SC, Harrington ME (1979). Calcium-dependent release of putative neurotransmitters in the chick visual system. Neuroscience 4: 1521-1527.

Bowen SE (2006). Increases in amphetamine-like discriminative stimulus effects of the abused inhalant toluene in mice. Psychopharmacology (Berl) 186: 517-524.

Brodie MS, Shefner SA, Dunwiddie TV (1990). Ethanol increases the firing rate of dopamine neurons of the rat ventral tegmental area in vitro. Brain Res 508: 65-69.

Brog JS, Salyapongse A, Deutch AY, Zahm DS (1993). The patterns of afferent innervation of the core and shell in the 'accumbens' part of the rat ventral striatum: immunohistochemical detection of retrogradely transported fluorogold. J Comp Neurol 338: 255-278.

Cairney S, Maruff P, Burns CB, Currie J, Currie BJ (2005). Neurological and cognitive recovery following abstinence from petrol sniffing. Neuropsychopharmacol 30: 1019-1027. 
Calderon-Guzman D, Hernandez-Islas JL, Espitia Vazquez IR, Barragan-Mejia G, Hernandez-Garcia E, del Angel DS et al (2005). Effect of toluene and cresols on $\mathrm{Na}+\mathrm{K}+-\mathrm{ATPase}$, and serotonin in rat brain. Regul Toxicol Pharmacol 41: 1-5.

Cameron DL, Wessendorf MW, Williams JT (1997). A subset of ventral tegmental area neurons is inhibited by dopamine, 5-hydroxytryptamine and opioids. Neuroscience 77: 155-166.

Carlezon Jr WA, Haile CN, Coppersmith R, Hayashi Y, Malinow R, Neve RL et al (2000). Distinct sites of opiate reward and aversion within the midbrain identified using a herpes simplex virus vector expressing GluR1. J Neurosci 20: 62RC.

Carlezon Jr WA, Nestler EJ (2002). Elevated levels of GluR1 in the midbrain: a trigger for sensitization to drugs of abuse? Trends Neurosci 25: 610-615.

Cragg SJ, Greenfield SA (1997). Differential autoreceptor control of somatodendritic and axon terminal dopamine release in substantia nigra, ventral tegmental area, and striatum. J Neurosci 17: 5738-5746.

Cruz SL, Mirshahi T, Thomas B, Balster RL, Woodward JJ (1998). Effects of the abused solvent toluene on recombinant $\mathrm{N}$-methyl-D-aspartate and non-N-methyl-D-aspartate receptors expressed in Xenopus oocytes. J Pharmacol Exp Ther 286: 334-340.

Deutch AY, Goldstein M, Baldino Jr F, Roth RH (1988). Telencephalic projections of the A8 dopamine cell group. Ann NY Acad Sci 537: 27-50.

Filley CM (2004). The effects of toluene on the central nervous system. J Neuropathol Exp Neurol 63: 1-12.

Flanagan RJ, Ives RJ (1994). Volatile substance abuse. Bull Narc 46: 49-78.

Ford CP, Mark GP, Williams JT (2006). Properties and opioid inhibition of mesolimbic dopamine neurons vary according to target location. J Neurosci 26: 2788-2797.

Funada M, Sato M, Makino Y, Wada K (2002). Evaluation of rewarding effect of toluene by the conditioned place preference procedure in mice. Brain Res Brain Res Protoc 10: 47-54.

Garriott JC, Foerster E, Juarez L, de la GF, Mendiola I, Curoe J (1981). Measurement of toluene in blood and breath in cases of solvent abuse. Clin Toxicol 18: 471-479.

Gerasimov MR, Ferrieri RA, Schiffer WK, Logan J, Gatley SJ, Gifford AN et al (2002a). Study of brain uptake and biodistribution of $\left[{ }^{11} \mathrm{C}\right]$ toluene in non-human primates and mice. Life Sci 70: 2811-2828.

Gerasimov MR, Schiffer WK, Marstellar D, Ferrieri R, Alexoff D, Dewey SL (2002b). Toluene inhalation produces regionally specific changes in extracellular dopamine. Drug Alcohol Dependence 65: 243-251.

Gonzales RA, McNabb J, Yim HJ, Ripley T, Bungay PM (1998). Quantitative microdialysis of ethanol in rat striatum. Alcohol Clin Exp Res 22: 858-867.

Grace AA, Bunney BS (1983). Intracellular and extracellular electrophysiology of nigral dopaminergic neurons-1. Identification and characterization. Neuroscience 10: 301-315.

Grace AA, Bunney BS (1984). The control of firing pattern in nigral dopamine neurons: burst firing. J Neurosci 4: 2877-2890.

Hutter OF, Kostial J (1954). Effect of magnesium and calcium ions on the release of acetylcholine. J Physiol (Lond) 124: 234-241.

Hyman SE, Malenka RC (2001). Addiction and the brain: the neurobiology of compulsion and its persistence. Nat Rev Neurosci 2: 695-703.

Ikai Y, Takada M, Shinonaga Y, Mizuno N (1992). Dopaminergic and non-dopaminergic neurons in the ventral tegmental area of the rat project, respectively, to the cerebellar cortex and deep cerebellar nuclei. Neuroscience 51: 719-728.

Ikemoto S, Wise RA (2004). Mapping of chemical trigger zones for reward. Neuropharmacology 47: 190-201.

Johnson SM, Trussell DC, McRitchie DA, Halliday GM, Hardman CD (1996). Anatomical and immunohistochemical identification of catecholaminergic neurones in brain slice preparations used in electrophysiology. J Neurosci Methods 64: 83-93.

Johnson SW, North RA (1992). Two types of neurone in the rat ventral tegmental area and their synaptic inputs. J Physiol 450: 455-468.

Katz B (1970). On the quantal mechanism of neural transmitter release, Nobel Lecture, December 12, 1970.

Katz B, Miledi R (1970). Further study of the role of calcium in synaptic transmission. J Physiol 207: 789-801.

Kishi R, Harabuchi I, Ikeda T, Katakura Y, Miyake H (1993). Acute effects of trichloroethylene on blood concentrations and performance decrements in rats and their relevance to humans. $\mathrm{Br} J$ Ind Med 50: 470-480.

Kishi R, Harabuchi I, Ikeda T, Yokota H, Miyake H (1988). Neurobehavioural effects and pharmacokinetics of toluene in rats and their relevance to man. Br J Ind Med 45: 396-408.

Kondo H, Huang J, Ichihara G, Kamijima M, Saito I, Shibata E et al (1995). Toluene induces behavioral activation without affecting striatal dopamine metabolism in the rat: behavioral and microdialysis studies. Pharmacol Biochem Behav 51: 97-101.

Lammers JHCM, van Asperen J, de Groot D, Rijcken WRP (2005). Behavioural effects and kinetics in brain in response to inhalation of constant or fluctuating toluene concentrations in the rat. Environ Toxicol Pharmacol 19: 625-634.

Lee DE, Gerasimov MR, Schiffer WK, Gifford AN (2006). Concentration-dependent conditioned place preference to inhaled toluene vapors in rats. Drug Alcohol Depend 85: 87-90.

Lena C, Changeux JP, Mulle C (1993). Evidence for 'preterminal' nicotinic receptors on GABAergic axons in the rat interpeduncular nucleus. J Neurosci 13: 2680-2688.

Lo PS, Chen HH (2005). Immunohistochemical localization of toluene-induced c-Fos protein expression in the rat brain. Toxicol Lett 157: 151-160.

Magnusson AK, Sulaiman MR, Dutia MB, Tham R (1998). Effects of toluene on tonic firing and membrane properties of rat medial vestibular nucleus neurones in vitro. Brain Res 779: 334-337.

Marinelli M, Rudick CN, Hu XT, White FJ (2006). Excitability of dopamine neurons: modulation and physiological consequences. CNS Neurol Disord Drug Targets 5: 79-97.

Meredith TJ, Ruprah M, Liddle A, Flanagan RJ (1989). Diagnosis and treatment of acute poisoning with volatile substances. Hum Toxicol 8: 277-286.

Meulenberg CJW, Vijverberg HPM (2003). Selective inhibition of [gamma]-aminobutyric acid type A receptors in human IMR-32 cells by low concentrations of toluene. Toxicology 190: 243-248.

NSDUH (2003). The NSDUH report [electronic resource: http:// oas.samhsa.gov/nhsda/2k3nsduh/2k3ResultsW.pdf]/National Survey on Drug Use and Health. 2003. Office of Applied Studies, US Dept of Health \& Human Services, SAMHSA, 2003; National Survey on Drug Use and Health (US) United States. Substance Abuse and Mental Health Services Administration Office of Applied Studies: Rockville, MD.

Paxinos G, Watson C (1988). The Rat Brain Atlas. Academic Press: San Diego.

Pickel VM, Chan J (1990). Spiny neurons lacking choline acetyltransferase immunoreactivity are major targets of cholinergic and catecholaminergic terminals in rat striatum. J Neurosci Res 25: 263-280.

Riegel AC, Ali SF, French ED (2003). Toluene-induced locomotor activity is blocked by 6-hydroxydopamine lesions of the nucleus accumbens and the mGluR2/3 agonist LY379268. Neuropsychopharmacology 28: 1440-1447.

Riegel AC, French ED (1999a). An electrophysiological analysis of rat ventral tegmental dopamine neuronal activity during acute toluene exposure. Pharmacol Toxicol 85: 37-43. 
Riegel AC, French ED (1999b). The susceptibility of rat nondopamine ventral tegmental neurons to inhibition during toluene exposure. Pharmacol Toxicol 85: 44-46.

Riegel AC, French ED (2002). Abused inhalants and central reward pathways: electrophysiological and behavioral studies in the rat. Ann NY Acad Sci 965: 281-291.

Robinson DL, Volz TJ, Schenk JO, Wightman RM (2005). Acute ethanol decreases dopamine transporter velocity in rat striatum: in vivo and in vitro electrochemical measurements. Alcohol Clin Exp Res 29: 746-755.

Rodd ZA, Bell RL, Zhang Y, Murphy JM, Goldstein A, Zaffaroni A et al (2005). Regional heterogeneity for the intracranial selfadministration of ethanol and acetaldehyde within the ventral tegmental area of alcohol-preferring (P) rats: involvement of dopamine and serotonin. Neuropsychopharmacology 30: 330-338.

Rodd ZA, Melendez RI, Bell RL, Kuc KA, Zhang Y, Murphy JM et al (2004b). Intracranial self-administration of ethanol within the ventral tegmental area of male wistar rats: evidence for involvement of dopamine neurons. J Neurosci 24: 1050-1057.

Rodd-Henricks ZA, McKinzie DL, Crile RS, Murphy JM, McBride WJ (2000). Regional heterogeneity for the intracranial self-administration of ethanol within the ventral tegmental area of female Wistar rats. Psychopharmacology (Berl) 149: 217-224.

Rodd-Henricks ZA, Melendez RI, Zaffaroni A, Goldstein A, McBride WJ, Li TK (2002). The reinforcing effects of acetaldehyde in the posterior ventral tegmental area of alcoholpreferring rats. Pharmacol Biochem Behav 72: 55-64.

Rosenberg NL, Grigsby J, Dreisbach J, Busenbark D, Grigsby P (2002). Neuropsychologic impairment and MRI abnormalities associated with chronic solvent abuse. J Toxicol Clin Toxicol 40: 21-34.

Sanghera MK, Trulson ME, German DC (1984). Electrophysiological properties of mouse dopamine neurons: in vivo and in vitro studies. Neuroscience 12: 793-801.

Schiffer WK, Lee DE, Alexoff DL, Ferrieri R, Brodie JD, Dewey SL (2006). Metabolic correlates of toluene abuse: decline and recovery of function in adolescent animals. Psychopharmacology (Berl) 186: 159-167.

Scholfied CN (1981). Electrophysiology of isolated mammalian CNS preparations. In: Kerkut GA, Wheal HV (eds). Electrophysiology of Isolated Mammalian CNS Preparations. Academic Press: New York. pp 133-152.

Sonders MS, Zhu SJ, Zahniser NR, Kavanaugh MP, Amara SG (1997). Multiple ionic conductances of the human dopamine transporter: the actions of dopamine and psychostimulants. J Neurosci 17: 960-974.

Spanagel R, Weiss F (1999). The dopamine hypothesis of reward: past and current status. Trends Neurosci 22: 521-527.

Stengard K (1994). Effect of toluene inhalation on extracellular striatal acetylcholine release studied with microdialysis. Pharmacol Toxicol 75: 115-118.

Stengard K, Hoglund G, Ungerstedt U (1994). Extracellular dopamine levels within the striatum increase during inhalation exposure to toluene: a microdialysis study in awake, freely moving rats. Toxicol Lett 71: 245-255.

Stengard K, O’Connor WT (1994). Acute toluene exposure decreases extracellular gamma-aminobutyric acid in the globus pallidus but not in striatum: a microdialysis study in awake, freely moving rats. Eur J Pharmacol 292: 43-46.

Stengard K, Tham R, O'Connor WT, Hoglund G, Ungerstedt U (1993). Acute toluene exposure increases extracellular GABA in the cerebellum of rat: a microdialysis study. Pharmacol Toxicol 73: $315-318$.

Takagi M (1984). Actions of cholinergic drugs on cells in the interpeduncular nucleus. Exp Neurol 84: 358-363.

Trulson ME, Trulson TJ, Arasteh K (1987). Recording of mouse ventral tegmental area dopamine-containing neurons. Exp Neurol 96: 68-81.
Tsuga H, Haga T, Honma T (2002). Effects of toluene exposure on signal transduction: toluene reduced the signaling via stimulation of human muscarinic acetylcholine receptor $\mathrm{m} 2$ subtypes in CHO cells. Jpn J Pharmacol 89: 282-289.

Tsuga H, Honma T (2000). Effects of short-term toluene exposure on ligand binding to muscarinic acetylcholine receptors in the rat frontal cortex and hippocampus. Neurotoxicol Teratol 22: 603-606.

Tsuga H, Wang RS, Honma T (1999). Effects of toluene on regulation of adenylyl cyclase by stimulation of G-protein-coupled receptors expressed in CHO cells. Jpn J Pharmacol 81: 305-308.

Tzschentke TM (2001). Pharmacology and behavioral pharmacology of the mesocortical dopamine system. Prog Neurobiol 63: 241-320.

Van Bockstaele EJ, Pickel VM (1995). GABA-containing neurons in the ventral tegmental area project to the nucleus accumbens in rat brain. Brain Res 682: 215-221.

Wang T, French ED (1993a). Effects of phencyclidine on spontaneous and excitatory amino acid-induced activity of ventral tegmental dopamine neurons: an extracellular in vitro study. Life Sci 53: 49-56.

Wang T, French ED (1993b). Electrophysiological evidence for the existence of NMDA and non-NMDA receptors on rat ventral tegmental dopamine neurons. Synapse 13: 270-277.

Washio HM, Inouye ST (1978). The effect of calcium and magnesium on the spontaneous release of transmitter at insect motor nerve terminals. J Exp Biol 75: 101-112.

Weiss B, Wood RW, Macys DA (1979). Behavioral toxicology of carbon disulfide and toluene. Environ Health Perspect 30: 39-45.

Westerink BH, Kwint HF, deVries JB (1996). The pharmacology of mesolimbic dopamine neurons: a dual-probe microdialysis study in the ventral tegmental area and nucleus accumbens of the rat brain. J Neurosci 16: 2605-2611.

Westerink BHC, Enrico P, Feimann J, De Vries JB (1998). The pharmacology of mesocortical dopamine neurons: a dual-probe microdialysis study in the ventral tegmental area and prefrontal cortex of the rat brain. J Pharmacol Exp Ther 285: 143-154.

Westerink RHS, Klompmakers AA, Westenberg HGM, Vijverberg HPM (2002). Signaling pathways involved in $\mathrm{Ca} 2+-$ and $\mathrm{Pb} 2+$-induced vesicular catecholamine release from rat $\mathrm{PC} 12$ cells. Brain Res 957: 25-36.

Westerink RHS, Vijverberg HPM (2002). Toluene-induced, $\mathrm{Ca} 2+$-dependent vesicular catecholamine release in rat $\mathrm{PC} 12$ cells. Neurosci Lett 326: 81-84.

Wise RA (2002). Brain reward circuitry: insights from unsensed incentives. Neuron 36: 229-240.

Wu LT, Ringwalt CL (2006). Inhalant use and disorders among adults in the United States. Drug Alcohol Depend 85: 1-11.

Yeomans JS (1989). Two substrates for medial forebrain bundle self-stimulation: myelinated axons and dopamine axons. Neurosci Biobehav Rev 13: 91-98.

Yim HJ, Gonzales RA (2000). Ethanol-induced increases in dopamine extracellular concentration in rat nucleus accumbens are accounted for by increased release and not uptake inhibition. Alcohol 22: 107-115.

Yin R, French ED (2000). A comparison of the effects of nicotine on dopamine and non-dopamine neurons in the rat ventral tegmental area: an in vitro electrophysiological study. Brain Res Bull 51: 507-514.

Zangen A, Ikemoto S, Zadina JE, Wise RA (2002). Rewarding and psychomotor stimulant effects of endomorphin-1: anteroposterior differences within the ventral tegmental area and lack of effect in nucleus accumbens. J Neurosci 22: 7225-7233.

Zangen A, Solinas M, Ikemoto S, Goldberg SR, Wise RA (2006). Two brain sites for cannabinoid reward. J Neurosci 26: 4901-4907.

Zapata A, Shippenberg TS (2005). Lack of functional D2 receptors prevents the effects of the D3-preferring agonist (+)-PD 128907 on dialysate dopamine levels. Neuropharmacology 48: 43-50. 